\title{
Finite Element Analysis for Optimization of Arch Dam Shape
}

\author{
Li Jun ${ }^{1, a}$,Wang Yuan-hui ${ }^{1, b}$
}

${ }^{1}$ School of Civil Engineering and Architecture, Kaifeng University, Henan Kaifeng 475004,China

\author{
aL1979394@163.com, ${ }^{\mathrm{b} w y h 2031 @ s o h u . c o m ~}$
}

Keywords: Arch dam; Shape Optimization; Finite Element; Arch-cantilever Method; Stress

\begin{abstract}
In this paper, logarithmic spiral arch ring is selected and finite element method is used to perform stress analysis and shape optimization and propose a program optimization of arch dam shape basing on arch-cantilever method, which plays an important role in improving safety of arch dam, reducing cost, and enhancing design level of arch dam.

Arch dam shape optimization is a key problem for the design of arch dam. Research on the method of arch dam shape optimization plays an important role in improving safety of arch dam, reducing cost, and enhancing design level of arch dam[1].
\end{abstract}

\section{Parametric modeling of dam foundation and dam}

Arch dam is a shell structure, which comprises single curvature dam and double curvature dam[2-3]. There are various forms of horizontal arch rings for arch dam. At the time of modeling, the apex of upstream face of crown cantilever section will be considered as coordinate origin, centerline of arch dam as $y$-axis (downstream direction as positive), and vertically downward direction as $z$-axis. Moreover, the direction of $x$-axis is the direction vertical to the river according to right-hand rule (left bank direction as positive).

\section{Design of arch dam shape}

\subsection{Layout of arch dam}

For the arch dam to be calculated, the elevation of dam crest is $415 \mathrm{~m}$, the elevation of lowest foundation surface of riverbed is $315 \mathrm{~m}$, and the maximum dam height is $90 \mathrm{~m}$. The valley at dam site is steep at left bank and smooth at right bank, which can be considered symmetrically using bedrock surfaces. See Fig. 1 for schematic diagram of semi-chord length at downstream side of arch dam. Valley width at axis of dam crest is $280 \mathrm{~m}$.

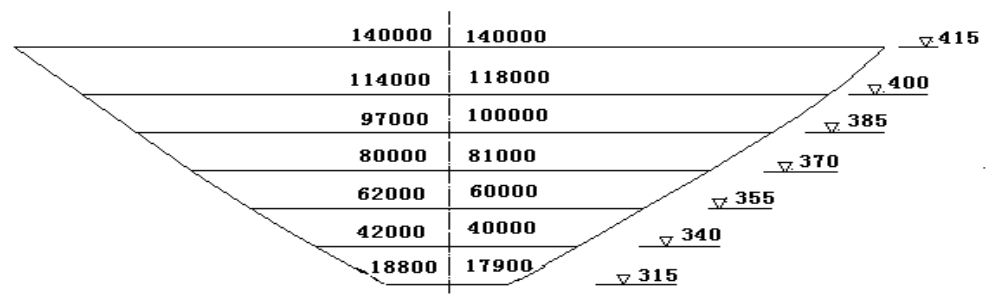

Fig. 1 Schematic diagram of semi-chord length at downstream side of arch dam

Left bank at dam site has a better stability condition of arch support, while the shoulder of right bank has adverse fissure cutting combination due to cutting of slope at downstream of arch support at right bank by terrain gullies. To strengthen stability of right arch support, it will be better to move the right arch side towards upstream as much as possible without moving the left arch side so as to increase the angle between contours of tangential direction at arch side and slope at right bank side[4-6]. 


\section{Analysis and calculation}

\subsection{Calculation of dam stress}

(1) Load combination

Condition (1): Normal water level in reservoir and corresponding tailwater level + Designed normal temperature drop + Self-weight + Sediment pressure

Condition (2): Dead water level in reservoir and corresponding tailwater level + Designed normal temperature rise + Self-weight + Sediment pressure

(2) Stress analysis

Arch-cantilever method will be used to divide the whole dam into 7 arches and 13 cantilevers (see Fig. 2). Engineering practice shows that 5 arches and 9 cantilevers, or 6 arches and 11 cantilevers, or 7 arches and 13 cantilevers will have sufficient calculation precision. The result indicates that the calculated stress value will be a little larger after density increase of cantilever.

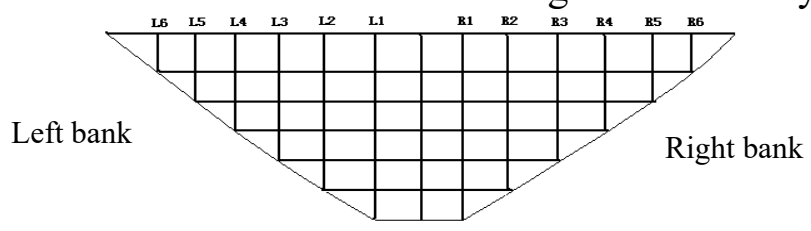

Fig. 2 Diagram for division of cantilever dams.

See Fig. 3 - Fig. 4 for contour map for stress on upstream and downstream dam faces for arch

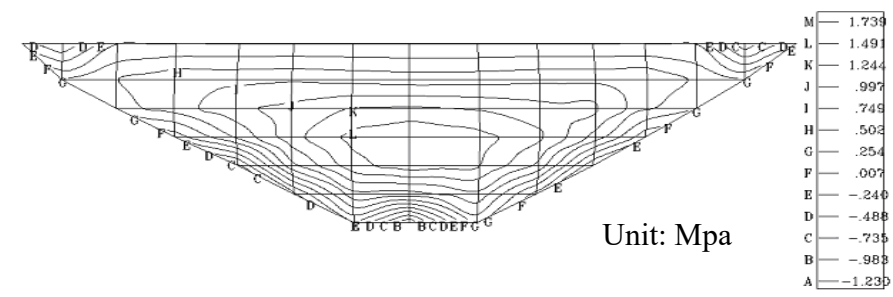

Fig. 3 Condition (1) - The first principle stress for upstream dam face

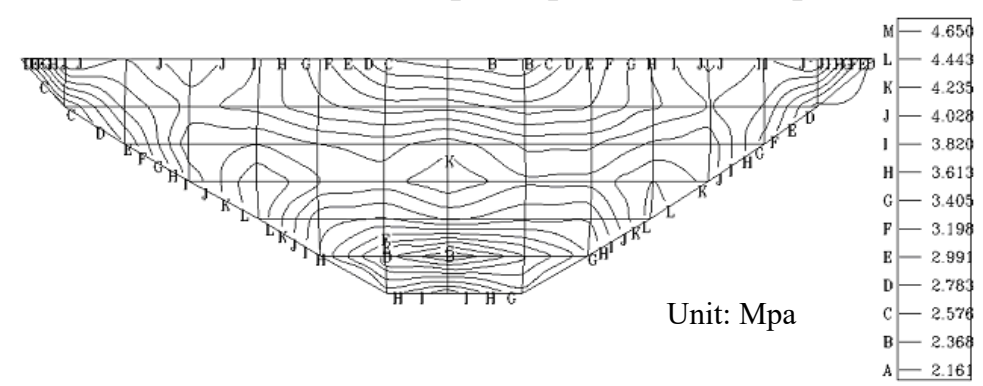

Fig.4 Condition (2) - The second principle stress for downstream dam face

\subsection{Stress analysis for dam}

Condition (1): The maximum compressive stress on upstream occurs around the arch crown with the elevation of $360-440$, and the maximum tensile stress occurs at dam bottom. The maximum compressive stress on downstream occurs at arch support with elevation of $325 \mathrm{~m}$, and the maximum tensile stress occurs at the positions on L1 cantilever and R1 cantilever with elevation of $343 \mathrm{~m}$.

Condition (2): The maximum compressive stress on upstream occurs at arch ring of dam crest, and the maximum tensile stress occurs at dam bottom. The maximum compressive stress on downstream occurs at arch support with elevation of $362 \mathrm{~m}$, and the maximum tensile stress occurs at the arch support of right bank with elevation of $402 \mathrm{~m}$.

The maximum stress value of dam is listed in the following Table 1. 
Table 1 Maximum stress value of dam

\begin{tabular}{|c|c|c|c|c|}
\hline Condition & $\begin{array}{c}\text { Maximum tensile } \\
\text { stress of dam face } \\
\text { on upstream (MPa) }\end{array}$ & $\begin{array}{c}\text { Maximum } \\
\text { compressive stress } \\
\text { of dam face on } \\
\text { upstream (MPa) }\end{array}$ & $\begin{array}{c}\text { Maximum tensile } \\
\text { stress of dam face } \\
\text { on downstream } \\
\text { (MPa) }\end{array}$ & $\begin{array}{c}\text { Maximum } \\
\text { compressive stress } \\
\text { of dam face on } \\
\text { downstream (MPa) }\end{array}$ \\
\hline Condition (1) & 0.90 & 3.26 & 0.58 & 3.68 \\
\hline Condition (2) & 0.78 & 3.26 & 0.54 & 4.22 \\
\hline
\end{tabular}

The compressive stresses are all in the permissible stress range, and the tensile stresses play the prominent function. Tensile stresses in Condition (1) and Condition (2) are all smaller than 1.0 Pa.

\section{Analysis on optimized results}

\subsection{Volume of arch dam}

Volume of arch dam will be taken as the target for optimization. The theoretical volume of arch dam after optimization is $22.5 \times 10^{4} \mathrm{~m}^{3}$. The volume of dams below following elevations is listed in Table 2.

Table 2 Volume of dams below following elevations

\begin{tabular}{|c|c|c|c|c|c|c|c|}
\hline Elevation $(\mathrm{m})$ & 325 & 340 & 355 & 370 & 385 & 400 & 419 \\
\hline Volume $\left(10^{4} \mathrm{~m}^{3}\right)$ & 0.00 & 2.86 & 5.66 & 11.28 & 14.80 & 18.52 & 24.65 \\
\hline
\end{tabular}

After the optimization, the thickness of dam crest for double curvature dam is $5.0 \mathrm{~m}$, the bottom thickness of crown cantilever is $24.0 \mathrm{~m}$, and the thickness - height ratio is 0.26 , which is a medium thickness arch dam. The length of center arc at dam bottom is $52.0 \mathrm{~m}$, and the length of center arc at top is $318.6 \mathrm{~m}$.

The dam stress is uniformly distributed, and the tensile stress is small within a small range. This satisfies the control standard for stress and foundation bearing capacity which is advantageous to the stability of arch support.

\section{Conclusion}

The calculation result indicates that finite element method can better simulate non-uniformity of foundation and complexity of geological structure by the combination of features of optimization of arch dam body as well as the comprehensive consideration of various factors. In addition, the optimization can also be restricted and controlled according to opinions from experts. Moreover, the result shows stable convergence. The shape is flatter and more beautiful and the dam stress is more uniform after optimization with slight change of the maximum principle stress and tensile stress.

\section{References:}

[1] Zhu Bofang, Research on Control Standard for Stress of Arch Dams [J]. Journal of Hydroelectric Engineering 2000 (12): 39 - 44.

[2] Ren Qingwen, and Wang Bole, Discussion on Flexibility Coefficient of Arch Dams [J]. Journal of Hohai University (Natural Science Page) 2003, 31(1): 1-4

[3] Wang Jiwei, and Zhang Xiongwen, Rules for Design and Calculation of Finite Elements for Hydraulic Reinforced Concrete Structure [J], Progress on Water Resources and Hydropower Technologies, 2005, 25(5): 44-47

[4] Zhou Wei, Ye Lin and Li Pujian etc. Research on Logarithmic Spiral and Logarithmic Spiral Arch Dams [J], Progress on Water Resources and Hydropower Technologies, 2008, 24(3): 66-69

[5]Bai Baozhong, and Zhong Yuanqing, Research on Control Standard of Design Stress of Concrete 
Arch Dams [J], Yangtze River, 2003, 34(11): 12-13

[6] Xiao Weirong, Optimization of Arch Dams Shape basing on Finite Element ANSYS: Thesis for Master Degree, Kunming University of Science and Technology, 2005 